\title{
RESENHA
}

\section{DOMINGUES, I. “FILOSOFIA NO BRASIL. LEGADOS E PERSPECTIVAS. ENSAIOS METAFILOSÓFICOS". SÃO PAULO: ED. UNESP, 2017. 561P**}

Oswaldo Giacoia Junior** ogiacoia@hotmail.com

Em Ivan Domingues um impecável ethos acadêmico transpõe-se também na esfera de sua atuação pública, intervindo no debate político e cultural, no exercício de cargos de representação, nos quais foi responsável por iniciativas decisivas, nos âmbitos do ensino, da pesquisa, da inovação e da extensão. Um protagonismo que levou à criação do Núcleo de Estudos do Pensamento Contemporâneo, grupo interdisciplinar da Universidade Federal Minas Gerais que consolidou rica expertise em biotecnologias e regulações éticas, jurídicas e políticas; mas que também marcou as gestões de Ivan Domingues, que fizeram história, como coordenador de área do conhecimento em instituições como a CAPES e no CNPq. Justifico a recordação desses dados biográficos como necessidade para resgatar o pano de fundo biográfico, intelectual e institucional, de onde emerge a obra ora publicada - um sólido background essencialmente marcado pela epistemologia.

"Filosofia no Brasil" é uma obra em estrita afinação com a trajetória filosófica do autor, e Ivan Domingues não seria o epistemólogo que é, pioneiro entre nós no campo das relações entre filosofia e ciências humanas, se permanecesse num registro unicamente historiográfico. Em vez disso, fiel à sua formação acadêmica, Domingues sintetiza também nessa obra diferentes perspectivas interdisciplinares, consciente de que o problema da filosofia no Brasil se inicia

* Resenha submetida em 04/01/18. Aceita em 22/02/18.

** Universidade Estadual de Campinas. Campinas - SP - Brasil. 
pela problematização de sua própria existência e natureza, assim como por suspeições concernentes à sua relevância.

Em consonância com tais coordenadas, "Filosofia no Brasil" constitui-se num conjunto de ensaios reunindo legados e perspectivas a respeito de um objeto que o próprio livro ajuda a conformar: a filosofia tal como esta se atualizou no Brasil ao longo de uma história distendida do período colonial aos nossos dias. Trata-se de uma obra que se constrói a partir de um vértice metafilosófico, e que, portanto, de modo algum deve ser confundida com um livro de história da filosofia. Nele Ivan Domingues faz uso independente, criativo e teoricamente fecundo do recurso aos tipos ideais, cunhados na Sociologia por Max Weber, para caracterizar as diferentes modalidades nas quais e pelas quais uma racionalidade de tipo propriamente filosófico realizou-se diferencialmente no Brasil, sob a influência de condicionantes socioeconômicas, políticas e culturais que vincam a realidade brasileira.

Firmada nas bases teóricas e metodológicas que dão sustentação à sua "Filosofia no Brasil", o ducto argumentativo de Ivan Domingues deixa atrás de si os trilhos desgastados que até então determinaram os rumos nos quais o problema da existência de uma autêntica filosofia no Brasil foi (mal)entendido ao longo de décadas. Além e aquém da alternativa supostamente incontornável que opõe uma filosofia brasileira ou do Brasil a uma filosofia feita no Brasil - evitando a cilada consistente em assumir como ponto de partida da argumentação uma determinada concepção hegemônica de Filosofia, para então descartar a possibilidade de que haja ou tenha havido uma experiência filosófica genuinamente brasileira -, Domingues se esforça por reconstituir as distintas figuras de racionalidade filosófica que se tornaram historicamente efetivas entre nós, seja no quadro de uma sociedade com uma economia de tipo agrário-rural, seja na passagem desse tipo de organização socioeconômica para o modelo urbano-industrial de configuração. Tais mudanças deixam suas marcas nas modalidades diversas em que tem se realizado entre nós a experiência filosófica, e que Ivan Domingues reconstitui com um instrumentário metodológico que leva em conta a natureza da obra, bem como os vínculos que a ligam tanto com a dimensão de sua autoria, como a instância que a produz, assim como com o público ao qual é destinada.

Desse modo, cada um dos ensaios que compõem o livro é consagrado a um dos momentos marcantes da experiência sócio-histórico-econômica brasileira, no interior de cujos marcos culturais vem a configurar-se uma racionalidade filosófica específica - tipicamente brasileira -, que se expressa num ethos filosófico tipificador, a que Ivan Domingues faz corresponder também um tipo de ratio particular. Estes são os legados e perspectivas, reunidos, organizados e interpretados sob uma ótica metafilosófica, que apreende o que neles há de 
racionalidade filosófica, ao mesmo tempo idiossincrática, tipicamente brasileira, mas como modalização da universalidade própria da filosofia.

Trata-se, então, de ensaios tendo por eixo o cruzamento entre a metafilosofia e a história intelectual, a história da filosofia e a exegese filosófica como fonte, meio e ferramenta, não como tema, problema ou objeto. O verdadeiro objeto, ou o problema do livro, encontra-se situado na confluência entre duas vertentes: uma delas é, como já dito, a vertente metafilosófica, em grande parte lastreada nos embasamentos históricos da filosofia nacional, com recurso às obras de João Cruz Costa, Paulo Eduardo Arantes, Henrique Cláudio de Lima Vaz, Silvio Romero, Tobias Barreto e vários outros. A outra é a vertente da história intelectual, história de formação da intelligentia brasileira -dilatada ao longo do livro rumo à história social e cultural, acarretando a incorporação dos chamados pensadores do Brasil, e aqui os interlocutores privilegiados são Sérgio Buarque de Holanda e Antonio Candido, sem excluir a presença significativa de outras fontes científicas. Trata-se, portanto, de um cruzamento de perspectivas interdisciplinares, articuladas pelo labor rigoroso e metódico do epistemólogo experimentado.

O trabalho propriamente hermenêutico realizado no livro é estruturado com base numa hipótese axial: ela consiste em procurar a experiência filosófica e da intelectualidade lá onde tais experiências normalmente podem ser achadas, mais precisamente, onde elas se encontram objetificadas: a saber, nas instituições, nas revistas e nos livros, largamente evidenciada (a hipótese) no caso do intelectual orgânico da Igreja e do sistema de ensino dos jesuítas, assim como no caso do Scholar e da Faculdade de Filosofia, Letras e Ciências Humanas da Universidade de São Paulo, além daquela extração enorme saída do Sistema Nacional de PósGraduação da CAPES e espalhada hoje por todo o país. Tudo isso, no entanto, sem preocupação de exclusividade, mas consciente da necessidade de manterse aberto a outras possibilidades e variações, com a consequente exigência de introdução de complementos, contrapontos e hipóteses auxiliares ad hoc.

Com lastro nessas premissas, o recurso metodológico aos tipos ideais de Max Weber torna-se particularmente produtivo, ao permitir o delineamento meticuloso das figuras que constituem o âmago do livro, nas quais se combina tipificação abstrata e periodização histórica: [1] O clérigo colonial, ou o apostolado jesuítico, pautado pela ratio studiorum da Companhia de Jesus. Ao ethos da pedagogia jesuítica para o ensino da filosofia corresponde uma forma de ratio que é a do intelectual orgânico e da Colônia. [2] O intelectual estrangeirado do Império e da República Velha, cujo modelo é o diletante oriundo do universo do direito, e cuja ratio é marcada pelo estilo bacharelesco do intelectual oriundo das então denominadas 'ciências jurídicas e sociais', ou seja, do âmbito do Direito. [3] O 
intelectual do Brasil moderno, cujo modelo é o Scholar, e cuja ratio é haurida no estudo verticalizado e sistemático das obras dos pensadores matriciais da história da filosofia, tal como praticado no trabalho da Missão Francesa na Universidade de São Paulo, desde a fundação do Departamento de Filosofia da USP. A ratio assim constituída é instanciada, hoje, no Homo Qualis, bem como no Homo Lattes. [4] O filósofo profissional e público contemporâneo - fusão do erudito e do intelectual investido de uma missão política, cujas figuras mais emblemáticas na filosofia brasileira são José Arthur Giannotti, Marilena Chauí e Henrique Cláudio de Lima Vaz - o padre Vaz, tal como é mais conhecido. [5] Enfim, o filósofo cosmopolita globalizado, o polímata (de $\pi \mathrm{o} \lambda \nu \mu \alpha \theta \eta \dot{s}$ - que aprendeu muito), o homo universalis, ou o pensador de largos horizontes - figura especulativa e sondagem do futuro.

Se, ao longo de seu percurso, "Filosofia no Brasil. Legados e Perspectivas" vai construindo sua identidade diferencial em relação a um mero exercício de historiografia, nem por isso, no entanto, o livro deixa de lançar luzes sobre a história das perspectivas e legados de natureza filosófica que integram a história da intelectualidade brasileira. Por causa disso, o livro guarda um registro de suas parcerias e interlocuções, tanto expressas como tácitas, com segmentos próximos e distantes, como é particularmente o caso da "História da Filosofia do Brasil", de Paulo Margutti. Por causa disso, Domingues também, de certo modo, coloca-se a questão da filosofia no e do Brasil, ou da filosofia brasileira. E esta, como sabemos, foi, nas últimas décadas, uma vexata quaestio, fortemente marcada por uma atmosfera intelectual de intensa hostilidade e aberto conflito - quase nunca bem formulado, jamais adequadamente compreendido em seus verdadeiros elementos.

Ora, justamente nessa seara, este último livro de Ivan Domingues é, a meu ver, a mais completa e meritória contribuição e o mais bem-sucedido resultado do esforço para formular o pensamento desse conflito, entendendo-se a palavra etimologicamente, como probállō, o ato de lançar ou colocar diante de si o que se tem como questão, assunto ou dificuldade, como condição para descobrir algumas vias de solução. Nesse sentido, "Filosofia no Brasil" marca um momento de enorme importância para a comunidade filosófica brasileira, e isso porque a obra inaugura um novo patamar sobre o qual pode situar-se o debate sobre a filosofia no Brasil, e coloca sólidos alicerces para uma autêntica autocompreensão dos avatares da racionalidade filosófica histórica, tal como realizada ao longo da história do Brasil, incluindo a adequada compreensão de seu presente, bem como com perspectivas abertas sobre o futuro.

Numa apresentação de seu próprio livro, Ivan Domingues comparou a literatura e a filosofia no Brasil, e, nessa comparação, formulou a questão: "a 
pergunta que fica, portanto, é se um dia teremos o nosso Machado, o nosso Rosa e o nosso Kant em filosofia. E por que não? - bem poderia ser a resposta, na forma interrogativa, num misto de dúvida, de esperança e de desafio". Vale a pena refletir sobre essa pergunta à luz de uma outra contribuição notável de Ivan Domingues para a filosofia feita no Brasil. Com isso, chamo a atenção do leitor para a continuidade que existe entre este último livro de Domingues e o anterior: "O Continente e a Ilha".

Com efeito, também em "O Continente e a Ilha" a operação teórica e metodológica de base consistia em sintetizar perspectivas interdisciplinares, com vigoroso lastro empírico, com o objetivo de encontrar, nessa síntese, um poderoso elemento auxiliar para a contextualização dos fatores determinantes da formação de tradições filosóficas, com seus respectivos estilos intelectuais. Tratava-se então, lá como aqui, de reconstituir um horizonte histórico que se oferecesse como lastro, como âmbito de emergência e matriz para certos tipos de racionalidade filosófica, num gesto que desativa preconceitos arraigados, que alimentam generalidades vagas e reforçam a exterioridade de polarizações irrefletidas, gerando fatores que tanto impedem a situação de verdadeiros problemas, quanto o controle das argumentações.

É assim que "O Continente e a Ilha" mapeia as trilhas da filosofia contemporânea, descobrindo os pontos de aproximação e contato, bem como os de afastamento e confrontação, entre as tradições insulares e continentais. Penso que "Filosofia no Brasil" se vale, e muito, do aprendizado haurido das experiências que conduziram ao livro anterior. Em "O Continente e a Ilha", a conclusão apontava para a alternativa da "experiência existencial", para evitar as reduções tanto do logicismo (da tradição analítica) quanto o historicismo (reconstruções contextuais) da hermenêutica continental. Em diálogo com Geroges Canguilhem, Ivan Domingues indicava o "espaço da reflexão" como o terreno próprio da filosofia. Por espaço da reflexão, o autor entende um espaço que é, ao mesmo tempo, existencial, real e virtual, e consiste em quadros abstratos e conceitualizáveis, que organizam 'as coisas mesmas', e que remetem sempre à experiência, sendo comparáveis, e, por causa disso, abertos ao diálogo e suscetíveis de discussão. Em "O Continente e a Ilha", assim como em "Filosofia no Brasil", avultam tanto os ensaios quanto a importância de remissões a Montaigne - para destacar a potência da imaginação e as virtudes do gênero filosófico-literário dos ensaios. Poderíamos adivinhar aqui uma aproximação entre dois epistemólogos que refletem sobre a tarefa da filosofia num momento particularmente crítico de sua história. Talvez essas duas obras de Domingues pudessem ser lidas como ensaios nascidos dessa condição atual de crise da filosofia. 
Refiro-me aqui a um diálogo latente entre Ivan Domingues e Michel Foucault, já que ambos estão de pleno acordo quanto à importância do ensaio na presente atualidade da Filosofia. Tanto é assim que, a respeito do ensaio como gênero filosófico, Michel Foucault escreveu, no segundo volume da "História da Sexualidade 2: o Uso dos Prazeres" (p. 13), o seguinte:

Mas o que é filosofar hoje em dia - quero dizer, a atividade filosófica - senão o trabalho crítico do pensamento sobre o próprio pensamento? Se não consistir em tentar saber de que maneira e até onde seria possível pensar diferentemente em vez de legitimar o que já se sabe? Existe sempre algo de irrisório no discurso filosófico quando ele quer, do exterior, fazer a lei para os outros, dizer-lhes onde está a sua verdade e de que maneira encontrá-la, ou quando pretende demonstrar-se por positividade ingênua; mas é seu direito explorar o que pode ser mudado, no seu próprio pensamento, através do exercício de um saber que lhe é estranho. O 'ensaio' - que é necessário entender com a experiência modificadora de si no jogo da verdade, e não com a apropriação simplificadora de outrem para fins de comunicação - é o corpo vivo da filosofia, se, pelo menos, ela for ainda hoje o que era outrora, ou seja, uma 'ascese', um exercido de si, no pensamento. ${ }^{1}$

Ora, sabemos que o ensaio como o corpo vivo da filosofia constitui, em Foucault, um legado que é caudatário, com toda certeza, de Montaigne, mas também remete a seu nietzscheanismo visceral. E o que acontece do lado de Ivan Domingues? Alguma coisa mudou, nesse sentido, do "Continente e a Ilha" para "Filosofia no Brasil. Legados e Perspectivas. Ensaios Metafilosóficos" em relação ao presente e ao futuro da filosofia? Seria esse um vislumbre de resposta para a pergunta: será que um "dia teremos o nosso Machado, o nosso Rosa e o nosso Kant em filosofia. E por que não? - bem poderia ser a resposta, na forma interrogativa, num misto de dúvida, de esperança e de desafio". Seria esta uma pista que nos remete a um contorno um pouco menos esmaecido desse horizonte por onde deverá transitar, no Brasil, o intelectual cosmopolita?

1 FOUCAULT, M. "História da Sexualidade 2: O uso dos Prazeres". Trad. M. T. C. Albuquerque. Rio de Janeiro: Graal, 1984. 